A AUTORA

Maria Ignês Carlos Magno

Doutora em Ciências da Comunicação pela ECA/USP.

Professora do curso de Pedagogia do Centro Universitário Salesiano de São Paulo e da Universidade Anhembi Morumbi.

E-mail: unsig@globo.com

\title{
ARTE DO CINEMA
}

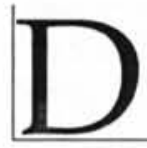

ia desses, quando revia filmes e textos sobre o cinema, pensei na ausência de uma preocupação com a cultura cinematográfica; no desconhecimento de obras fantásticas produzidas pelo cinema; na surpresa de um aluno quando projetei Un chien Andalou - Um cão Andaluz - (a seqüência inicial do filme de Buñuel é a imagem que a MTV usa sempre que tem algum problema em sua transmissão); do entusiasmo de outro aluno, contando que a avó já tinha visto todos os filmes expressionistas e que possuía $O$ gabinete do Dr. Caligari, de Fritz Lang. Lembrei-me também de que a maioria das escolas dispõe de uma sala e dia de vídeo e que o cinema, como todas as artes, pode ser lido sob diversos pontos de vista e perspectivas.

Temos tratado, na seção Videografia, das possibilidades de pesquisas e reflexões que os filmes nos oferecem. Trabalhamos as relações entre os filmes e a história, os filmes e os meios de comunicação, os filmes e a literatura, entre outros aspectos. Mas pouco ou quase nada vimos do cinema no seu fazer estético, na sua própria linguagem, ou mesmo propusemos a pergunta o que é o cinema? Como ele é feito? Ou ainda, nunca sugerimos uma investigação ou discussão sobre a sua própria história. Sobre o cinema arte, indústria, espetáculo, técnica, cultura, quase nada. Do cinema como representação da história e de si mesmo, apenas uma vez. Suas analogias com a pintura, a literatura, o teatro, indiretamente. No entanto, sabemos que o cinema, ao mesmo tempo em que é arte, que trabalha com nossos desejos, com nosso imaginário, "possui suas próprias características, tem sua dinâmica de produção da imagem (a câmera, a tela em que é projetado). É linguagem com suas próprias regras e convenções"'.

Retomei o prefácio do livro de Antônio Costa, Compreender o cinema, quando o autor escreve "hoje o cinema é visto sobretudo na televisão", pensei nos meus alunos, na composição dessa videografia e, sob pena de erro, resolvi arriscar e propor uma reflexão, um estudo e o conhecimento de peças cinematográficas que falam do cinema, de sua estética em relação a outras estéticas artísticas, de sua his-

1. COSTA, Antônio. Compreender o cinema. Trad. Nilson Moulin Louzada. 2.ed. São Paulo: Globo, 1989. 
tória e, principalmente, do amor e da paixão do fazer cinematográfico. Embora saiba que muitos são os filmes que mostram como o cinema é feito, optei por alguns dos títulos possíveis de serem encontrados e trabalhados. Numa seqüência cronológica, para facilitar a compreensão e o estudo, sugiro para essa videografia: Corrida de automóveis para meninos e Carlitos no estúdio, dois dos primeiros filmes de Charles Chaplin; $O$ último magnata, de Elia Kazan; A noite americana, de François Truffaut; $A$ idade do ouro, de Luiz Buñuel, $O$ gabinete do dr. Caligari, de Robert Wiene e $M$, o vampiro de Diisseldorf, de Fritz Lang.

CORRIDA DE AUTOMÓVEIS PARA MENINOS (Kid auto races at Venice) CARLITOS NO ESTÚDIO (Behind the Screen)

Diretor - Charles Chaplin

Ano - respectivamente 1914 e 1916

País - Inglaterra

Mudo, p\&b

Os filmes de Chaplin desse período não trazem uma ficha técnica detalhada. Mesmo assim são muito interessantes para iniciarmos uma discussão e pesquisa. Corrida de automóveis para meninos, extraído de uma carta enviada por Chaplin a uma namorada, é um verdadeiro documento sobre como se fazia cinema na época: muita improvisação e poucos recursos técnicos. Carlitos no estúdio nos apresenta, através de um confuso contra regra, os bastidores de um estúdio em um dia de rodagem muito atribulado.

Os dois filmes de Charles Chaplin, além de nos mostrarem de forma cômica os bas- tidores de uma filmagem, podem nos levar aos primeiros estudos sobre a história do nascimento da linguagem cinematográfica, em especial a construção estética do cinema mudo, seus códigos, suas especificidades. Podem nos ensinar a ver, admirar, estudar e começar a compreender porque não podemos olhar o cinema mudo, ou silencioso, com os mesmos olhos com que olhamos o cinema atual. Uma boa pesquisa é sobre a cor que, apesar de parecer o contrário, sempre foi usada no cinema.

Paralelamente ou antecedendo aos demais filmes, sugiro um exercício e a leitura de dois textos. O exercício consiste em organizar pequenos grupos de alunos para discutir e registrar o que é, para eles, o cinema. Após o painel e o registro das conclusões, propor a leitura dos textos: Cinema. A arte do real, e Cinema. A arte do real?, ambos do livro $O$ que é o cine$m a^{2}$, de Jean-Claude Bernardet. Em seguida, a classe deve assistir ao filme $O$ último magnata, de Elia Kazan. Se o grupo não dispuser de tempo suficiente para ver o filme todo (ideal), sugiro toda a primeira seqüência, quando um dos mais importantes estúdios de Hollywood é apresentado por um de seus mais antigos funcionários e, particularmente, a histórica cena em que Roberto De Niro, no papel do produtor Monroe Stahr, explica a um roteirista em crise o que é o cinema. Trata-se, segundo Costa, "de uma cena antológica, pela direção, pelo ritmo, pela filosofia do cinema enunciado"3.

Depois dos exercícios iniciais, o grupo não pode deixar de assistir a $A$ noite americana, de François Truffaut. Esse filme deve ser visto do começo ao fim pois nele, 
como a sinopse nos diz, tem-se uma declaração de amor ao cinema ou como um filme é feito. Uma outra história dos bastidores de uma filmagem.

\section{O ÚLTIMO MAGNATA}

Direção - Elia Kazan

Produção - 1976

Duração - 120min

País - EUA

Locadoras comerciais

Seguindo a sinopse que apresenta o filme, Hollywood nos anos de 1930 é como se fosse uma lenda, devido às suas incríveis produções. Para seus anos mais glamourosos, Hollywood encontrou o líder perfeito: Monroe Stahr, um jovem diretor de um expressivo estúdio e o responsável por muitos triunfos artísticos e financeiros. Stahr é uma combinação fascinante de executivo e gênio criativo: um idealista romântico, com grande sensibilidade para as finanças. O seu sucesso é sem paralelo, contudo não consegue o amor que tanto deseja. Fadado a realizar o sonho de muitos, mas não o seu.

\section{A NOITE AMERICANA (Day for Night) \\ Roteiro e Direção - François Truffaut, Jean-Louis Richard e Suzanne Schiffman. \\ Fotografia - Pierre-Willian Glenn \\ Ano - 1973 \\ Locadoras comerciais}

Esse filme, de acordo com a ficha de apresentação, é considerado uma obraprima e a consagração definitiva do diretor François Truffaut. Trata-se de uma declaração de amor ao cinema, um relato poético e sempre genial sobre os bastidores de uma filmagem. Truffaut reservou para si mesmo o papel do cineasta que conduz a produção de um filme, tentando contornar uma série de dificuldades: a crise de seu astro central, a chegada da estrela, a atriz veterana que não consegue decorar os diálogos.

Como o filme é uma grande homenagem ao cinema, Truffaut também homenageia grandes cineastas e nos abre a possibilidade de realizarmos uma pesquisa sobre cineastas, filmografias, a importância e a relação deles com movimentos culturais entre os anos $1920 \mathrm{e}$ 1930. Um dos cineastas é Jean Cocteau, cujo nome aparece numa tela pendurada numa das paredes dos cenários. Outro diretor é Orson Wells, personagem de um sonho que persegue um dos atores principais do filme. Pesquisa essa que pode servir de gancho para abordarmos um outro aspecto do cinema: as influências e as relações entre o cinema e os movimentos de vanguarda do início do século (1900-1930): o futurismo, o dadaísmo, o expressionismo e o surrealismo. As estéticas artísticas, seus representantes; as obras cinematográficas e a história; a primeira guerra, o período entre-guerras, a ascensão do nazifascismo, entre outras.

Pensando na dificuldade de encontrarmos todos os principais filmes do período, escolhi três deles que estão disponíveis nas locadoras: $A$ idade do ouro, de Buñuel; $O$ gabinete do $d r$ : Caligari (filme mudo) de Robert Wiene e $M$, o vampiro de Düsseldorf, (primeiro filme sonoro) de Fritz Lang. 
A IDADE DO OURO (L'âge D’or)

Direção - Luís Buñuel

Fotografia - Albert Duverger

Cenografia - Schilknecht

Música - Georges Van Parys (trechos

de Beethoven, Debussy e Wagner )

País - França

Ano -1930

Duração - 60min

Locadoras comerciais

Em $A$ idade do ouro, a sinopse que descreve a atmosfera do filme nos dá indícios do que veremos. Escorpiões vivem nas pedras. Trepado numa dessas pedras, um bandido avista um grupo de arcebispos que canta sentado numa paisagem mineral. $\mathrm{O}$ bandido corre para avisar os amigos da presença muito próxima dos arcebispos. Chegando à cabana, encontra os amigos num estranho estado de fraqueza e depressão... São jogados pela janela de um castelo: um pinheiro em chamas, um arcebispo, uma girafa, plumas e um enorme instrumento agrícola... Construído sobre o tema do amor opondo-se ao mundo externo e a seus preconceitos morais e sociais, o filme chocou Paris nos anos de 1930. Sua estréia foi tumultuada, os quadros de Dali, Max Ernest, Man Ray e Miró (artistas surrealistas e dadaístas) expostos no hall de entrada do cinema foram rasgados. "As violentas polêmicas e as intervenções de censura suscitadas por L'âge D'or, no qual o deboche aos valores burgueses e a um espírito anticlerical se contrapõe uma exaltação do valor subversivo do erotismo" ${ }^{4}$.
O GABINETE DO DR. CALIGARI

Direção - Robert Wiene

País - Alemanha

Ano-1919

Duração - 69min

Locadoras comerciais

Dr. Caligari é um marco do cinema expressionista alemão. Passou a designar um "estilo baseado em cenografias e métodos de representação de matriz teatral e pictórica, com o fim de exprimir uma visão deformada de situações e ambientes em sintonia com os argumentos que apresentam personagens decididamente patológicas e vivências marcadamente emblemáticas" ". O gabinete do dr: Caligari narra a história de uma série de delitos num pequeno vilarejo da fronteira holandesa, onde um misterioso hipnotizador, Dr. Caligari, chega acompanhado do sonâmbulo Cesare, que supostamente estaria adormecido por 23 anos. À noite, Cesare perambula pela cidade, matando inocentes até que um jovem estudante começa a suspeitar de Caligari.

\section{O VAMPIRO DE DÜSSELDORF \\ Direção - Fritz Lang \\ Roteiro - Fritz Lang e Thea von Harbou \\ País - Alemanha \\ Ano-1931 \\ Duração - 99min \\ Locadoras comerciais}

Primeiro filme falado de Fritz Lang, inspirado num fato real, deveria se chamar originalmente $O$ assassino está entre nós. Mas os nazistas acharam que isto 
poderia ser desonroso para a Alemanha. Sem músicas, no começo do cinema falado, o filme foi rodado quase exclusivamente em estúdio. Peter Lorre faz o papel de um sádico que assassinava crianças. Quando a polícia não consegue prendêlo, são os próprios marginais que se reúnem para condená-lo. Com os cenários estilizados e os tipos marcantes de marginais autênticos, o filme tem inúmeras cenas, que refletiram o clima de ascensão do nazismo, na Alemanha.

Os três filmes apontados pedem um trabalho conjunto com as áreas de História e Educação Artística. Fundamental será pesquisar e estudar as origens, as características estéticas e as relações e inter-relações histórico-culturais dos movimentos citados com as narrativas e a construção dos filmes. Afinal o que seria do cineasta, sem os olhos e do pintor, sem as mãos? Primeiras seqüências de Um cão Andaluz de Luís Buñuel e Salvador Dali.

Resumo: A autora propõe para a videografia deste número uma reflexão sobre a linguagem cinematográfica: como o cinema fala de si, conta sua própria história e mostra-se como linguagem. Destaca para esse objetivo clássicos do cinema mundial como: Corrida de automóveis para meninos, Carlitos no estúdio, ambos de Charles Chaplin; $O$ último magnata, de Elia Kazan; $A$ noite americana, de François Truffaut; $A$ idade de ouro, de Luis Buñuel; O gabinete do dr. Caligari, de Robert Wiene; e finalmente, $M$. O vampiro de Düsseldorf, de Fritz Lang.

Palavras-chave: cinema, linguagem cinematográfica, cinema mudo, cinema falado, arte, surrealismo
Como parte das sugestões, segue uma bibliografia básica para que o trabalho proposto seja realizado.

\section{BIBLIOGRAFIA}

ANDRADE, Ana Lúcia Menezes de. O filme dentro do filme: a metalinguagem no cinema. Belo Horizonte: UFMG,1999.

FERRO. Marc. Cinema e História. Trad. Flávia Nascimento. Rio de Janeiro: Paz e Terra, 1992.

EISNER, Lotte. A tela demoníaca. As influências de Max Reinhardt e do Expressionismo. Trad. Lúcia Nagib. Rio de Janeiro: Paz e Terra: Instituto Goethe, 1985.

KRACAUER, Siegfried. De Caligari a Hitler. Uma história psicológica do cinema alemão. Trad. Tereza Ottoni. Rio de Janeiro: Jorge Zahar, 1988

(The art of cinema)

Abstract: The author proposes, for this edition's videography, a reflection on cinematographic language: how does cinema talk about itself, tell its own story and show itself as a language. For this, it emphasizes world cinema classics such as: Kid Auto Races at Venice and Behind the Screen, both by Charles Chaplin; Elias Kazan's The Last Tycoon; François Truffaut's La Nuit Americaine, Luis Buñel's L'Age d'Or, Robert Wiene's The Cabinet of Dr. Caligari; and, finally, Fritz Lang's $M$. The vampire of Dússeldorf

Key words: cinema, cinematographic language, silent movies, spoken movies, art, surrealism 